\title{
Recent Advances in Cast Iron Structure and Properties Ultrasonic Testing and Flaw Detection
}

\author{
Liubov Voronkova \\ ROSATOM Scientific Centre of Russian Federation JSC RPA “CNIITMASH”, Russia \\ voronkova-lv@yandex.ru
}

Keywords: ultrasonic testing, iron castings, structure, temporary resistance at stretching, cast iron welded joints

\begin{abstract}
The advantage of ultrasonic testing of iron castings prior to destructive control consists of an impressive reduction in time and costs, as well as of the ability to assess the quality of the metal anywhere on the castings. By evaluating the acoustic characteristics of cast iron it is possible to determine the form of graphite in it and its strength. The presence of chill in the metallic base and the thickness of the chilled layer can also be determined by ultrasonic method. The use of electronic signal processing allows to distinguish it from high structural noise, which makes possible the testing of cast iron for a thickness of several meters. The use of transducers with phased array is the basis of the flaw detection of containers for nuclear waste from cast iron with globular graphite with a thickness of $500 \mathrm{~mm}$.
\end{abstract}

\section{Introduction}

For the first time the attention of researchers Himchenko N. V. [1] and Ziegler R. [2] has been turned by on the connexion between the graphitic inclusions form and amount and the propagation velocity of a longitudinal ultrasonic wave. The velocity of a longitudinal wave of ultrasound $\mathrm{V}_{\mathrm{l}}$, the size depending on the Young's modulus, changes along with of the form of graphite, fig. 1.

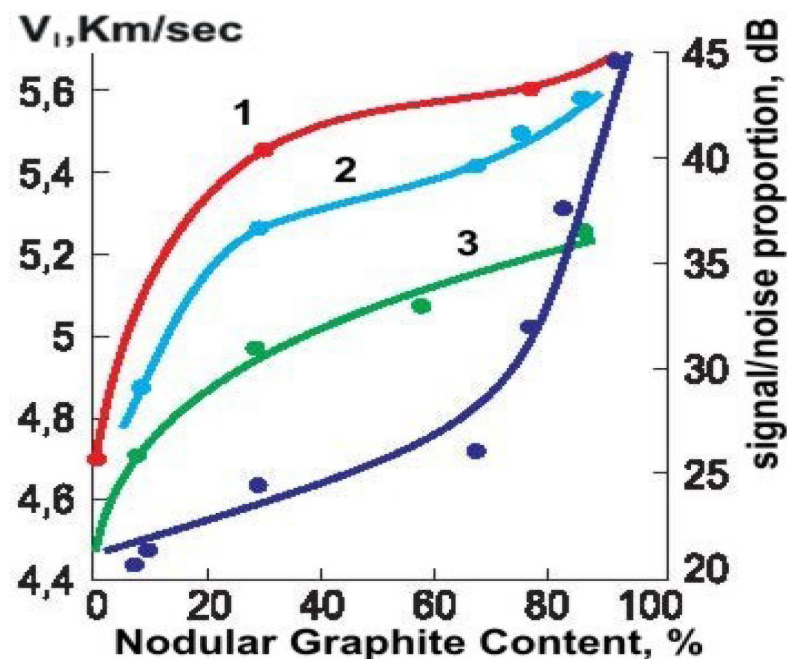

Fig. 1. Influence of the globular graphite size and content on the longitudinal wave speed: 1 - small graphite, 2 - average, 3 - large, the signal/noise proportion.

The type of dependence is invariable, but the curve can move on ordinate axis along with the change of the graphitic inclusions amount. For various thicknesses of castings and technologies of their receiving the boundary size of $\mathrm{V}_{1}$ between the globular form and the vermicular form of graphite fluctuates from $5,10 \mathrm{~km} / \mathrm{s}$ (thick-walled castings) to the value of $5,50 \mathrm{~km} / \mathrm{s}$ provided in the majority of publications.

With the content of carbon, the size and the form of graphite inclusions being invariable it is possible to track the influence of structure of a metal basis (the content of cementite) of cast iron on his acoustic characteristics.

The cast iron containing cementite in the metal basis usually has overestimated $\mathrm{V}_{1}$ (fig. 2). 


\section{$\mathrm{V}_{1}, \mathrm{Km} / \mathrm{sec}$}

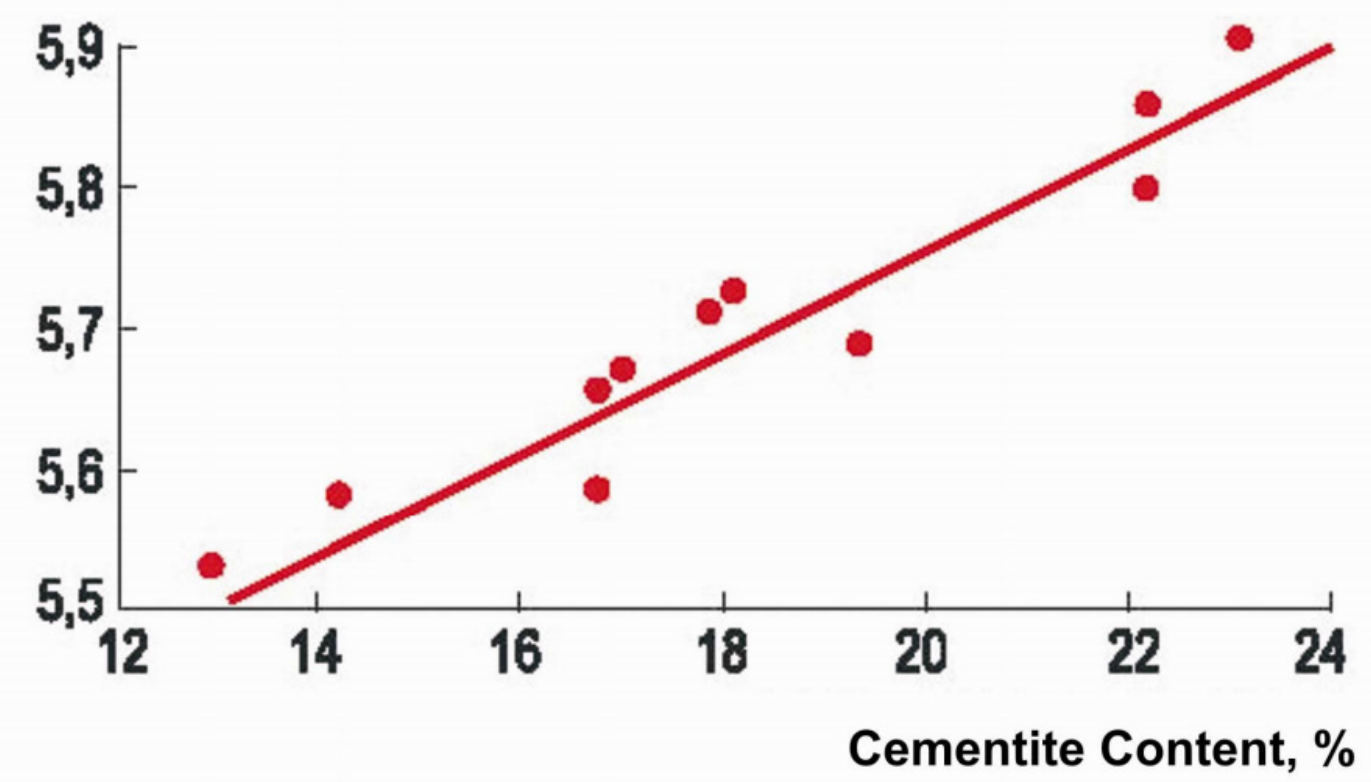

Fig. 2. Influence of cementite content in a cast iron metal basis with globular graphite on the size of propagation velocity of a longitudinal ultrasonic wave.

If a layer contains cementite it is important to know its thickness. In case of indistinct border with the chilled layer the propagation velocity of a surface ultrasonic wave (fig. 3) can be used.

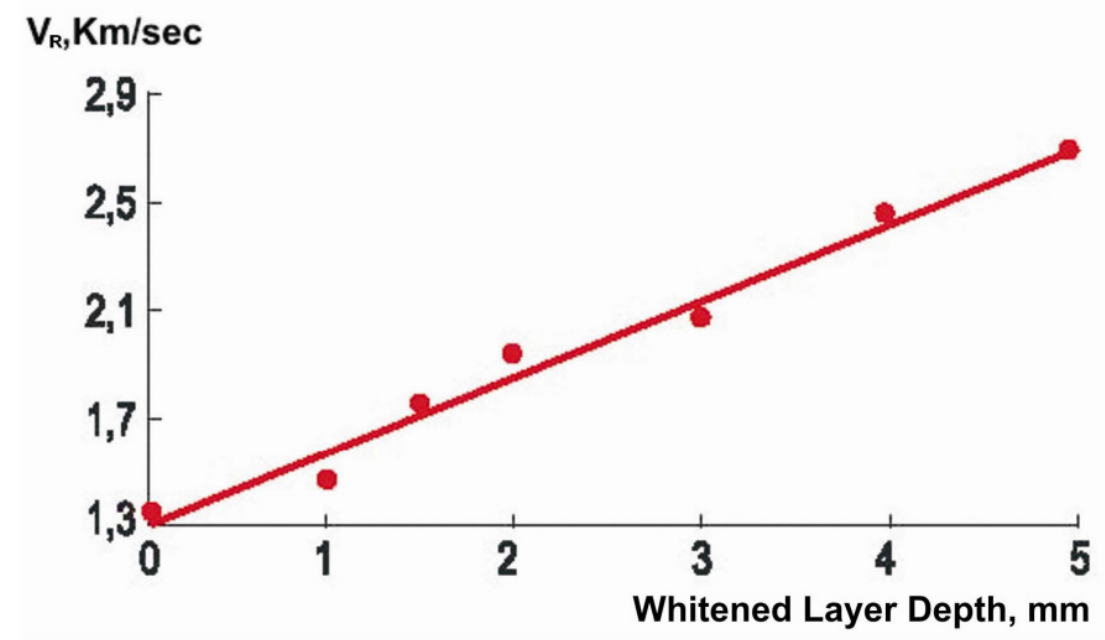

Fig. 3. Dependence of the surface ultrasonic wave propagation velocity on the chilled layer depth in gray cast iron.

Now there is a possibility of assessment by the ultrasonic method of such important characteristic of cast iron as durability. Reliable ultrasonic control of cast iron mechanical properties is possible when their dependence from the Young's modulus takes place. It first of all concerns the temporary resistance at stretching of $\sigma_{\mathrm{B}}$ defined on special explosive samples.

In [3] the direct proportionality existence between $\sigma_{B}$ and $E$ and the HB hardness of cast iron are indicated:

$$
\sigma_{\mathrm{B}}=\alpha \cdot \mathrm{E} \cdot \mathrm{HB},
$$

where $\alpha$ is the coefficient defined empirically, depends on the type of cast iron and on the technology of its production.

It is necessary to consider the following equation (Eq. 2) as a physically reasonable dependence [4]: 


$$
\sigma_{\mathrm{B}}=\alpha_{1} \cdot \mathrm{V}_{l}^{2} \cdot \mathrm{HB}
$$

where $\alpha_{1}$ is the coefficient defined empirically, depends on the type of cast iron and on the technology of its production.

The error of definition of $\sigma_{B}$ doesn't exceed $7 \%$.

\section{Experiment 1}

New application of the cast iron ultrasonic testing method was offered for destruction possibility definition of a mold from gray cast iron after a series of pouring an austenitic steel fusion in it [5].

Steel temperature was $1550^{\circ} \mathrm{C}$ when releasing out of the furnace. From one melting of the weight of $1000 \mathrm{~kg}$ two ingots were casted in two molds. The hardened ingots were maintained during 25-30 min. Mold walls of the thickness of $60 \mathrm{~mm}$ got warm to $650-700^{\circ} \mathrm{C}$ in the top part. Molds cooled in a natural way to the internal surface temperature of $200-300^{\circ} \mathrm{C}$, further were painted and put under filling. The turnover cycle of molds were about 2 hours. Molds failed suddenly, due to the formation of vertical through thermal cracks in corners through which the considerable volume of steel leaked. For prevention of unexpected destructions, it is planned to carry out the monitoring of structure condition in cast iron mold.

The new mold has a graphite content of the number of $5-8 \%$, the length of inclusions is 30-60 microns. Structure of cast iron of the mold has passed to exploitation, numerous thermal loadings of graphite are of $12 \%$, the amount of inclusions is of 120-250 microns.

Results and Discussion. Such microstructure of cast iron, being characterized by the large inclusions, the raised volume share of lamellar graphite and existence of an essential share of ferrite in mainly pearlite metal basis has influenced on the reduction of $14 \%$ of the velocity size of a longitudinal ultrasonic wave. This result is received not on samples but on real castings. Practical result of the real researches is the establishment of boundary value of velocity of longitudinal ultrasonic fluctuations $(4040 \mathrm{~m} / \mathrm{s})$ in cast iron of molds of this design to define limit number of pourings out, providing the operation of molds without emergency destruction with an effluence of liquid steel.

Velocity of ultrasonic wave in cast iron with the known thickness of the mold wall was determined in an echo - impulse mode by time of arrival of a bottom echo-signal which has been, as a rule, disguised by white and structural noise. For the noise influence reduction in the equipment we used broadband frequency-modulated emission signals with an average frequency of $1 \mathrm{MHz}$ with the subsequent filtration of an echo signal. The results of the measurements are given in Table 1.

Table 1 . The values of dependence of the ultrasonic longitudinal wave velocity on the cast iron mold microstructure

\begin{tabular}{|c|c|}
\hline Molds description & $\begin{array}{c}\text { The ultrasonic longitudinal wave } \\
\text { velocity values }[\mathrm{m} / \mathrm{s}]\end{array}$ \\
\hline New & $4280-4340$ \\
\hline Before destruction & $4020-4040$ \\
\hline Collapsed & $3740-3750$ \\
\hline
\end{tabular}

\section{Main Development Trends}

In ultrasonic flaw defection of cast iron there are 2 main development trends - testing of cast iron welded joins and big thickness control (up to $500 \mathrm{~mm}$ ).

For the control of big thickness $(500 \mathrm{~mm})$ of the containers for nuclear waste from cast iron with globular graphite only transducers with phased array are applied [6]. 
The cylindrical barrel at an intermediate stage of production with an approximate length of $6 \mathrm{~m}$, with the diameter of $2,5 \mathrm{~m}$ is controlled. The frequency is $1,5 \mathrm{MHz}$, we use a 64-element array, eight various directions, longitudinal and transverse waves.

The sensitivity requirement is the detection of disk reflectors with a diameter of $6 \mathrm{~mm}$ at various orientations. In an adjusting sample 54 reflectors with various orientations have been made.

For any options, a good signal/noise ratio is observed.

Flat-bottomed openings of the diameter of $6 \mathrm{~mm}$ can be found with a sufficient stock of sensitivity and the distance of more than $3 \mathrm{~m}$. The system works since the beginning of 2016 and yields reproduced results. The size of a found flaw is less than $5 \mathrm{~mm}$.

\section{Experiment 2}

Welded joints of cast iron exist in repair and joining of pipes in a lash (on 5 pieces) before transportation. Butt ring welded joints of pipes from cast iron with globular graphite with a diameter of $120 \mathrm{~mm}$ and $6 \mathrm{~mm}$ thick, fig. 4 have been investigated on [7], with the application for testing.

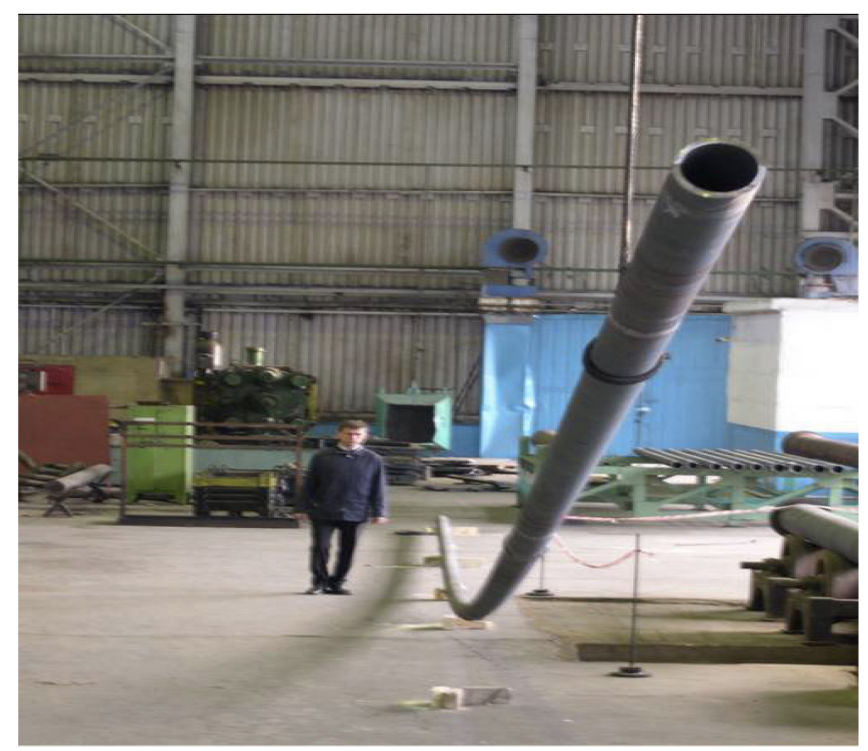

Fig. 4. Ring butt welded joints of pipes. A lash of five pipes.

The structure of cast iron of a seam and alloy age zone differs a little, but the small thickness of this zone $(0,2 \mathrm{~mm})$ practically doesn't influence the velocity values of a longitudinal ultrasonic wave.

Flaw detection of welded joints was carried out by a standard procedure, in fig. 5 the image from the flaw detector "OmniScan" screen is submitted, the 64-element transducer with phased array, the frequency of $5 \mathrm{MHz}$, angle of probe $70^{\circ}$ was used.

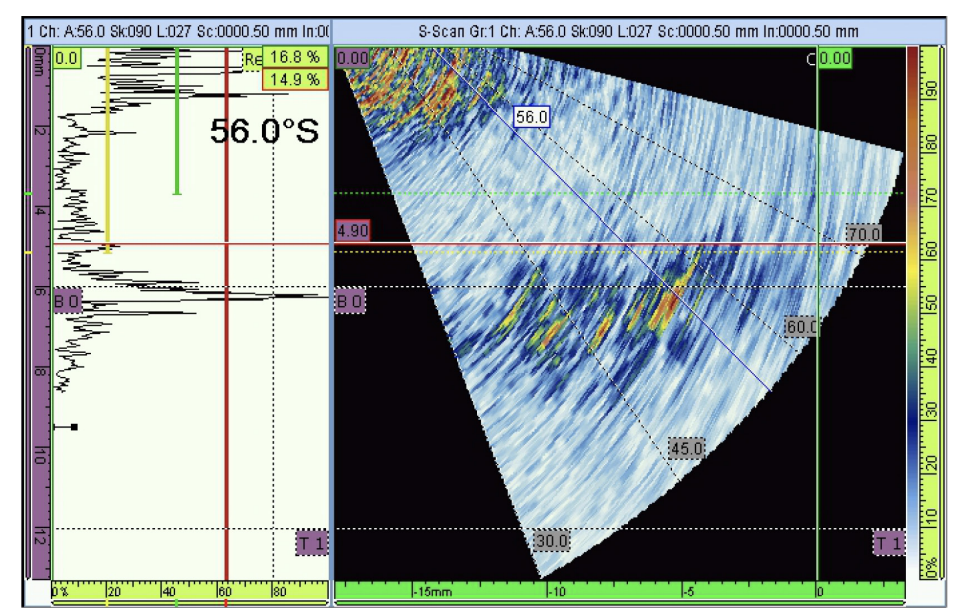

Fig. 5. A and S- sweep with the echo signal image from an angular reflector $2 \mathrm{x} 1 \mathrm{Mm}$ in the built-up metal of welded ring join of pipes diameter 120x6m from cast iron with spherical graphite. 
Results and discussion. The echo signal from an angular reflector of $2 \times 1 \mathrm{~mm}$ is considerably (more than $12 \mathrm{~dB}$ ) allocated from structural noise that forms a basis for confident ultrasonic flaw detection of welded joints of cast iron with globular graphite.

\section{Conclusion}

Ultrasonic testing of cast iron actively develops in three directions - flaw detection, structure analysis and mechanical properties determination (Fig. 6). The physical foundation is laid. The main regularities are known. There is no standard technical documentation, but this is the business of the future.

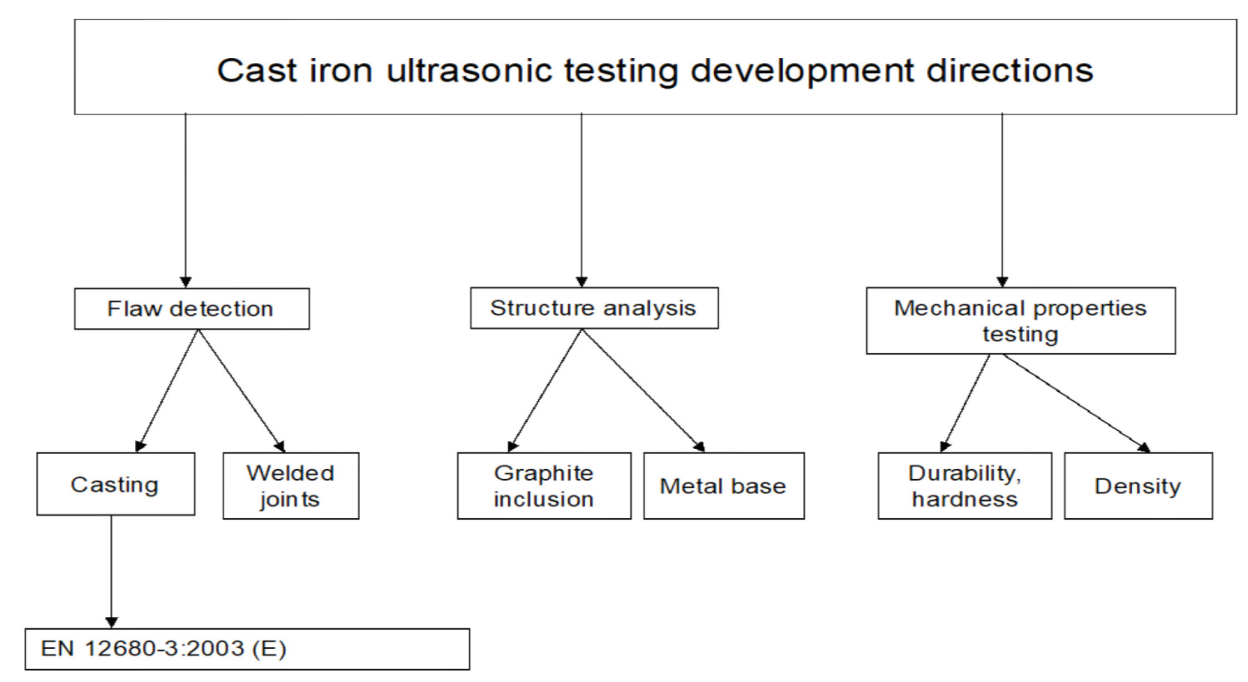

Fig. 6. Development directions of ultrasonic testing cast iron.

\section{References}

[1] N.V. Himchenko, V.N. Prikhodko, Ultrasonic control of size of graphitic inclusions in gray cast iron, The Factory laboratory no. 12 (1955) 1470-1488.

[2] R. Ziegler, R. Gertner, Die Scallgereschwindigkeit als Keenzeichnendl Grobe fur die Beirteilung von Gußeisen, Giesserei 45 (10) (1958) 185-193.

[3] A. Thum, H. Ude, Die Elastizität und die Schwingungsfestigkeit des Gusseisens. [The elasticity and the fatigue strength of cast irons.], Giesserei 16 (1929) 501-513.

[4] L.V. Voronkova, Ultrasonic control of mechanical properties of cast iron castings, Factory laboratory no. 7 (1993) 26-27.

[5] V.V. Andreyev, L.V. Voronkova, F.A. Nuraliyev, V.K. Kachanov, Investigation into cast iron structure degradation in ingot mold operation by the change of its acoustic characteristics, Liteinoe Proizvod. 12 (1) (2015) 14-16.

[6] T. Shmitte, N. Chichkov, O. Nemitz, T. Hinz, D. Geller, T. Orth, H. Hocks, D. Opalla, J. Frank, Automated Ultrasonic Testing of Large Casted Cask Bodies Using Phased Array Techniques, 19th WCNDT. (2016) We.4. E.3.

[7] L.V. Voronkova, V.A. Nosov, Ultrasonic flaw detection of welding joint of cast iron tube real possible, Kontrol'. Diagn. 3 (2010) 20-22. 